\title{
Julian Bream e a Luteria
}

\author{
Ricardo Dias
}

Brasil

$\mathrm{J}$

ulian Bream sempre foi um individualista, um self made man. Interessado em música, seu pai, que tocava cançôes populares e jazz, o ensinou rudimentos de acompanhamento. Ele seguiu por conta própria. Um dia, uma gravação de Recuerdos de La Alhambra, de Francisco Tárrega, por Andrés Segovia, mudou seu foco: era aquilo que queria fazer pelo resto da vida. E fez, apesar da estranheza que, na época, um violonista inglês causava: violão era para espanhóis. Seu pai levou-o a uma reunião de uma sociedade de violonistas amadores próxima, e o presidente desta, o russo Boris Perrott, aceitou-o como aluno. Era um professor pouco inspirado, e fosse eu dado a lugares-comuns, diria: em pouco tempo o aluno superou o mestre. Não estaria mentindo e, à falta de expressão melhor, mantenho o clichê, na esperança de que não acabe o leitor vendo em mim um escritor também pouco inspirado.

Sua ambição musical, então, levou-o ao Royal College of Music. Aprovado em seu dificílimo exame de admissão, gerou um problema para a vetusta instituiçãa: não havia curso de violão. Então nosso herói, à falta de melhor opção, formou-se em composição e piano. Acabou sendo uma coisa boa, the proporcionando uma visão mais ampla do espectro musical. De qualquer forma, naquela época muito pouca gente teria algo a lhe ensinar no nosso instrumento. Houve uma tentativa, um tanto exótica, de transformar Bream numa espécie de valete de Segovia, acompanhando-o em turnês. A ideia estapafúrdia não foi adiante, evidentemente. Se isso ocorresse, o mais provável seria um estrangular o outro.

Violonistas não costumam associar fatores externos ao tocar de seus ídolos. Na música popular, dificilmente João Gilberto - e consequentemente a bossa-nova - teriam existido sem os violóes Di Giorgio, especificamente feitos para corda de nylon. Basta experimentar tocar aqueles 
acordes em um instrumento com cordas de aço (padrão até então) para entender o porquê. Segovia foi casado com uma não musicista, depois com uma pianista, em seguida com uma cantora, a brasileira Olga Coelho. Fazer uma associação de suas gravações com seus casamentos pode ser bem interessante e ilustrativo: o jovem virtuoso cheio de dedos passa a dominar a polifonia e, em seguida, aprende a deixar a música “respirar”. O próprio Bream sustenta que Tárrega resolveu ampliar seu (hoje nosso) repertório após começar a tocar o violão feito por Antonio de Torres, o "pai” de nosso instrumento, que deu suas dimensóes finais e mostrou todo o lirismo que poderia haver dentro daquela pequena caixa em forma de 8 .

Invejando a sinergia entre Segovia e seu violão, construído pelo alemão Hermann Hauser em 1937, Bream passou a carreira buscando seu complemento. Acabou tendo o nome associado mais fortemente a dois luthiers: o espanhol José Romanillos e o inglês David J. Rubio. Mas, antes, uma palavrinha sobre alaúdes.

Nosso homenageado carrega o mérito de ter ressuscitado a música para alaúde da Inglaterra elisabetana. Usava um instrumento feito por seu conterrâneo Thomas Goff, mais conhecido como construtor de cravos. Não tenho como saber se a alteração foi feita a pedido dele, mas seu alaúde tinha um rastilho. Explicando:

Alaúdes usualmente têm um cavalete simples. As cordas são amarradas nele e pronto. No de Bream havia uma peça de osso após a saída das cordas (chamada "rastilho"), de forma a emprestar mais tensão e definição, como nos violões modernos. Além disso, ao invés dos trastes de tripa amarrados (padrão nos instrumentos originais), os tinha de metal, também emulando os violóes. Isso lhe valeu críticas, às quais respondeu mais ou menos assim: "Descobri músicas que não eram tocadas há mais de 300 anos, para virem me dizer que eu estava fazendo errado!”

Os alaúdes que teve desde então mantiveram essas características, todos, aliás, construídos pelo citado David Rubio. Mas vamos aos violóes.

Nos seus primeiros anos, Julian usou diversos instrumentos, nenhum digno de nota. Seu primeiro disco de violão solo, em 1955, foi gravado com um violão Hector Quine do mesmo ano. Depois usou Hausers (pai e filho), Robert Bouchet, Hernandez y Aguado... Teve muitos outros, menos mencionados: Gary Southwell, Brian Cohen, Kevin Aram, Jeffrey Elliott, todos profissionais de primeira linha.

Bream teve a chance de comprar uma enorme propriedade rural, na Inglaterra. Na borda das 
terras havia uma cocheira desativada, e achou que seria perfeito usar esse espaço para uma oficina de luteria. Acabou convidando o luthier David Rubio para ocupá-la, e assim foi feito. Já adianto que ele ficou cerca de dois anos, um reparador de pianos o substituiu e Romanillos foi seu último ocupante, até que o proprietário resolveu vender essa parte das terras.

Trabalhar sob as vistas de um violonista - além do mais um violonista genial e cheio de ideias próprias - é a ideia de inferno para um luthier. Existe um aforismo na profissão que diz que "eunucos e clientes sempre sabem como as coisas devem ser feitas”. E quando os luthiers são igualmente geniais, pode-se imaginar que os atritos devam ser constantes.

Bream tinha algumas ideias fechadas: o violão ou nasce bom ou adeus, não considerava o amadurecimento como fator; achava que violóes tinham que ser leves; dizia que Jeffrey Elliott jamais deveria se mudar de Portland, EUA, cidade extremamente chuvosa, pois seus violóes não funcionavam em tempo seco, e ia por aí. Isso limitava bastante a atuação dos construtores, agravada pela tristeza de ver o estrago que Bream fazia nos tampos. Uma piada maldosa dizia que era melhor evitar assistir a recitais dele na primeira fileira: lascas de madeira do tampo voavam. Mas nada disso diminui nossa dívida pelo seu apoio aos geniais Rubio e Romanillos.

Com este último há uma história curiosa. Sergio Abreu, hoje luthier, ainda em atividade como concertista, tinha um instrumento maravilhoso, um Hermann Hauser de 1930. Romanillos já havia feito uma cópia de um desses, de 1936, para Bream, com bastante sucesso. Sergio pediu-lhe que fizesse dois instrumentos baseado nas plantas do seu. Romanillos fez um primeiro e mostrou a Julian, ainda sem verniz, que não se interessou muito. Ficou guardado na oficina, foram construídos os dois dos irmãos Abreu (um deles destruído por um luthier que resolveu raspar seu verniz e colocar poliuretano em vez da maravilhosa goma-laca original. Equivale a colar uma placa de vidro no tampo, matando o som e os harmônicos. Fica aqui o alerta: não se modifica o verniz original de um instrumento), e a vida seguiu. Um dia, John Williams, o grande violonista, visitou Bream. Levaramno à oficina de Romanillos, então na propriedade, e no meio da conversa Julian perguntou se havia um violão disponível, queria demonstrar alguma coisa. Havia. Justamente aquele, que ele não havia gostado, já com verniz. Pegou o violão e não o soltou pelos anos seguintes. Era o agora famoso Romanillos de 1973. Não há registro de alguém ter questionado o fato de o violão ter melhorado com o tempo, apesar da crença de Bream...

A Julian Bream devemos algumas das principais músicas escritas para violão da segunda 
metade do século XX para cá. Nocturnal, Bagatelas, Sonatas, Royal Winter Music, Hill Runes, concertos... Devemos a redescoberta da música elisabetana para alaúde - e a fabricação de alaúdes, também. Todo um mercado ressurgiu graças ao apoio do fantástico inglês. Dois dos maiores luthiers de todos os tempos cresceram profissionalmente graças à sua ajuda. E mesmo brincando sobre suas exigências, trabalhar sendo medido pela régua de um gênio como ele ajuda qualquer profissional a se desenvolver. Se considerarmos que esses luthiers geraram, sem exagero, dezenas de seguidores, fica impossível mensurar a importância de Julian nesse processo. E, repetindo, com uma baliza muito alta, que é o que impulsiona qualquer profissão ou arte.

Termino essa história, da relação entre Bream e a luteria, com um final feliz, mas, primeiro, uma digressão: $\mathrm{O}$ americano Albert Augustine inventou as cordas de nylon. Ele e sua esposa Rose fundaram a indústria de cordas Augustine - a quem Julian sempre foi fiel, usava as "Red Labels" e, da coleção de ambos, em 1990 Rose emprestou a Bream um violão Hauser de 1940. Com esse instrumento Bream finalmente encontrou sua metade, seu par, seu complemento ideal. Sua busca havia terminado. Tocou-o até seu último recital, em 2002.

Aposentado, vendeu tudo o que tinha, ficando apenas com o suficiente para viver, uma casa modesta e seu fiel Romanillos de 73. Todo o resto foi usado para instituir o Julian Bream Trust, fundo destinado a patrocinar estudantes e a comissionar novas músicas. Mais um legado.

Se comecei este texto com um lugar comum, por uma questão de simetria devo terminar com outro: Bream nos deixou órfãos. Era insubstituível. Único. Ímpar. Quantos, como ele, conseguiram mudar a história de seu instrumento e da música de seu tempo? Julian o fez, certamente descansa em paz. ${ }^{1}$

\section{SOBRE O AUTOR}

Ricardo Dias (Rio de Janeiro, 10/04/1963) tem formação de violonista clássico, tendo estudado com Sergio de Pinna, Leo Soares, Henrique Pinto e Jodacil Damaceno. Desde 1985 se dedica à luteria, tendo estudado no atelier de Mario Jorge Passos. Como luthier, desenvolveu estudos em ergonomia, tendo instrumentos em diversas partes do mundo. Criou e

\footnotetext{
1 Este texto foi construído utilizando as seguintes fontes: a) Correspondência pessoal com Fabio Zanon; b) Correspondência pessoal com Sergio Abreu; c) Correspondência pessoal com José Romanillos; d) Artigo: Aram, Kevin: Julian Bream's 1973 Romanillos; e) Livro: Palmer, Tony: Julian Bream, A Life on the Road; f) Livro: Dias, Ricardo: Sergio Abreu, Uma Biografia; g) DVD: Julian Bream: My Life on Music; h) Website: julianbreamguitar.com
} 
ministrou um curso de luteria na Universidade Gama Filho, RJ. Fez palestras e participações em universidades e eventos, como MIMO, UFRJ, UFSJ, Vital Medeiros, etc. Jurado em concursos de música, como Associação de Violão do Rio de Janeiro e Villa Lobos de Vitoria, ES. Organizador de eventos, como o 1 Festival de Violão de Serra Negra, SP. Há quase 20 anos co-moderador do Fórum de Violão Erudito, com mais de 5000 membros e o maior do mundo em conteúdo exclusivo. Escreveu “Sergio Abreu, Uma Biografia”. Tem, no prelo, um guia sobre conservação de instrumentos. Escreveu diversos artigos em publicações especializadas. Participações diversas na gravação de diversos CDs, mais recentemente tendo feito a produção musical de "Vento Brando", de João Camarero. É compositor, letrista e escritor. ORCID: https://orcid.org/0000-0003-0953-444X. E-mail: eu@rdias.net 